\title{
Visualization of Flow Patterns in Closed Loop Flat Plate Pulsating Heat Pipe Acting as Hybrid Thermosyphons under Various Gravity Levels
}

Vincent Ayel, Lucio Araneo, Pietro Marzorati, Cyril Romestant, Yves Bertin \& Marco Marengo

To cite this article: Vincent Ayel, Lucio Araneo, Pietro Marzorati, Cyril Romestant, Yves Bertin \& Marco Marengo (2018): Visualization of Flow Patterns in Closed Loop Flat Plate Pulsating Heat Pipe Acting as Hybrid Thermosyphons under Various Gravity Levels, Heat Transfer Engineering, DOI: $10.1080 / 01457632.2018 .1426244$

To link to this article: https://doi.org/10.1080/01457632.2018.1426244

Jan 2018.

Submit your article to this journal ¿

Llll Article views: 11

Q View related articles $\sqsubset$

View Crossmark data ־ 


\section{ACCEPTED MANUSCRIPT}

\section{Visualization of Flow Patterns in Closed Loop Flat Plate Pulsating Heat Pipe Acting as Hybrid Thermosyphons under Various Gravity Levels}

\section{Vincent Ayel $^{\mathrm{a}}$, Lucio Araneo ${ }^{\mathrm{b}}$, Pietro Marzorati ${ }^{\mathrm{b}}$, Cyril Romestant $^{\mathrm{a}}$, Yves Bertin ${ }^{\mathrm{a}}$, and Marco Marengo ${ }^{\mathrm{c}}$}

${ }^{\text {a} P p r i m e ~ I n s t i t u t ~ C N R S ~-~ E N S M A ~-~ U n i v e r s i t e ́ ~ d e ~ P o i t i e r s, ~ F u t u r o s c o p e-C h a s s e n e u i l, ~ F r a n c e ~}$

${ }^{\mathrm{b}}$ Politecnico di Milano, Dipartimento di Energia, Milano, Italy

${ }^{c}$ University of Brighton, School of Computing, Engineering and Mathematics, Brighton, UK

Address correspondence to Dr. Vincent Ayel, Pprime Institut CNRS - ENSMA - Université de Poitiers, UPR 3346, 1, av. Clément Ader, BP40109, 86961 Futuroscope-Chasseneuil, France.

E-mail: vincent.ayel@ensma.fr

Phone: +33-5-4949-8112, Fax: +33-5-4949-8101 


\title{
ACCEPTED MANUSCRIPT
}

\author{
Abstract \\ A particular flat plate pulsating heat pipe (FPPHP), filled with FC72, is tested during the $62^{\text {th }}$ and \\ $64^{\text {th }}$ ESA parabolic flight campaigns under vertical orientation. The FPPHP is made of a thin \\ copper plate, in which a curved channel disposed with $11 \mathrm{U}$-turns is milled and closed on the top \\ face by a transparent borosilicate plate. The particular characteristics is that the equivalent \\ hydraulic diameter of the square channel $\left(2.5 \times 2.5 \mathrm{~mm}^{2}\right)$ is above the working fluid capillary \\ diameter on ground, inducing a stratification of the liquid/vapor phases under ground and hyper- \\ gravity conditions, whatever the orientation. The energy transfer mode in such conditions is \\ represented either by pure pool boiling inside the channels almost completely filled by the liquid \\ phase or by an annular flow pattern inside the channels mostly filled by the refrigerant vapor. \\ Instead, during the microgravity phases, the fluid regime naturally turns into a slug-plug flow \\ pattern. During the transition from $1.8 g$ to $0 g$ a rapid dry-out may occur in some of the channels, \\ followed by a similarly fast reaction of liquid plugs moving towards the evaporator from the \\ condenser zone. Such stop-and-start motion events continue during the whole microgravity \\ period, leading to strong temperature oscillations, but also to a still acceptable thermal \\ performance of the device.
}

\section{Introduction}

The Pulsating Heat Pipe (also called Oscillating Heat Pipe) is recently acquiring an increasing interest due both to the fascination for the complexity of the internal two-phase phenomena, and to novel applications, rapidly increasing the Technology Readiness Level of this device, both for ground and space environment. Especially looking at the potential application in space, even if a 


\section{ACCEPTED MANUSCRIPT}

practical implementation on a satellite or a space probe is still ahead in the future, the analysis of the thermo-fluid-dynamics in various regimes and in transient gravity condition is at the base of a major development of modeling and numerical techniques, which may help the understanding of the physics of other systems, like thermosyphons or grooved heat pipes.

In this paper a closed loop Flat Plate Pulsating Heat Pipe (FPPHP, Fig. 1) is tested under terrestrial, hyper- and micro- gravity conditions. As it is presently widely accepted, complex flow patterns, ranging from slug to annular flow, occur in the adjacent tubes of a pulsating heat pipe (PHP), initiated by local pressure instabilities [1-3], and influenced by many physical parameters [4-6]. Such flow patterns obviously alter the local and the total heat flux transferred between the heated to the cooled ends of the PHP. One of the most important parameter is the channel internal diameter, which drives the presence of a sharp liquid/vapor phase separation into liquid slugs and vapor bubbles by menisci [5]. Many other parameters deserve mention, including: the number of turns, PHP surface area, the filling ratio, the physical properties of the working fluid [7], the applied heat power, and, more important in the context of this study, the inclination with respect to gravity (for ground test conditions) or, generally, the change in the value of the device acceleration.

One of the major issues of PHPs operating under microgravity conditions is the existence of a slug flow pattern in the tube/channels, which cannot be evaluated according to the critical Bond number widely used in the literature in terrestrial conditions $\left(B o=\left[g\left(\rho_{l}-\rho_{v}\right) D_{c r i t} 2 / \sigma\right]^{1 / 2} \leq B o_{c r i t}\right)$. This point will be further discussed in the next section for the present FPPHP. However, if it has been demonstrated that capillary pulsating heat pipes can operate under microgravity conditions [8-12], and more recent studies from Mangini et al. [13,14] showed that the flow pattern 


\section{ACCEPTED MANUSCRIPT}

switched from stratified flow under normal or hyper gravity conditions to slug flow under microgravity conditions, for uniform heating patterns [13] as well as non-uniform heating patterns [14]. They tested a $3 \mathrm{~mm}$ internal diameter tubular PHP (well above the critical diameter value fixed at around $1.66 \mathrm{~mm}$ for the tested fluid, $\mathrm{FC} 72$, at $20^{\circ} \mathrm{C}$ ) with a transparent tube portion on the upper part of the bench above the condenser zone. Through a visualization with a high-speed camera, it was possible to capture that, in microgravity, the bubbles became perfectly symmetrical since the liquid is tending to fill the entire section of the channels. Such behavior supports encouraging results on PHP performance in absence of gravity: considering the slug flow pattern, the bigger the tube diameter, the lower the viscous and capillary pressures losses are opposing the overall fluid motion, thus promoting the mass, momentum and heat transfers along the tubes. However, one should keep in mind that with a larger tube diameter, the lower capillary forces hardly maintain the liquid plugs/vapor bubbles phase separation of the slug flow regime. Hence, the inertial forces linked to the fluid velocity will be able to destabilize such regime by breaking the menisci, according to the Weber number criterion $\left(W e=\rho_{l} v_{l}^{2} D / \sigma\right)$ - or the criteria suggested by Garimella et al. with the Reynolds number, i.e. considering also the viscous dissipation [13] -. To summarize, when operating pulsating heat pipes under microgravity conditions, a larger internal diameter should lead to better performance and higher power transfer, but also to a premature dry-out due to a rapid transition to a bubbly flow and the consequent stop of the flow motion. The critical limit of the internal diameter capable to maintain the characteristic slug/plug regime in microgravity conditions is still unknown. In addition for pulsating heat pipes tested under microgravity conditions, an intermittent thermofluid behavior has been observed by [13], as well as temperature fluctuations [12], whose origin 


\section{ACCEPTED MANUSCRIPT}

could be assigned to stop-and-start flow motions occurring inside the PHP during those phases. To this respect, this work aims at verifying if it is possible to replicate the results obtained for the tubular PHP also for the case of a FPPHP.

As already discussed by Ayel et al. [12], considering a copper FPPHP with hydraulic internal diameter equal to $1.65 \mathrm{~mm}$, just below the critical one of $1.66 \mathrm{~mm}$ with $\mathrm{FC} 72$ at $20^{\circ} \mathrm{C}$, and tested under normal and microgravity conditions, two evident features differentiate a FPPHP from a capillary tube PHP $[1,15]$ :

On one hand, square shape channels have sharp angles at the corners, acting like capillary grooves and assisting the liquid flow to the evaporator zone [16-18]. Such edges may also provoke the rupture of the cross-sectional menisci, causing a flow regime transition into an annular flow (for vertical orientation).

On the other hand, transverse heat spreading occurs among channels, due to the solid geometry continuity, leading to lower temperature gradients. This causes a balance of the pressure differences in the channels, i.e. of the main drivers of oscillations under the slug flow pattern regime. FPPHPs tested under horizontal inclination and microgravity conditions consequently often show early dry-out $[16,17]$, with a greater influence for larger channels.

From all these considerations, a semi-transparent glass/copper FPPHP with a hydraulic diameter above the standard critical capillary length for FC72 as a working fluid has been tested on ground and under hyper- and microgravity conditions during the ESA $62^{\text {th }}$ parabolic flight campaign. 


\section{ACCEPTED MANUSCRIPT}

\section{Experimental apparatus}

The tested FPHP was milled from a copper plate (width: $124 \mathrm{~mm}$, length: $204 \mathrm{~mm}$, thickness: 2.5 $\mathrm{mm}$ ) with a single rectangular shaped groove (width: $2.5 \mathrm{~mm}$, depth: $2 \mathrm{~mm}$ ). This single grooved channel forms a series of $11 \mathrm{U}$-turns in the evaporator (see Fig. 1, left). The copper plate was covered by a $5 \mathrm{~mm}$ thick transparent borosilicate glass (width: $120 \mathrm{~mm}$, length: $200 \mathrm{~mm}$ ), glued on the upper part thanks to a silicon glue (NUSIL CV7 2289 1P) chosen for its elastic properties considering the differential expansion between copper and borosilicate. The glue was deposited to guarantee a perfect sealing at the plate border. The adjacent channels were also sealed-off relative to one another. The thickness of the glue (about $0.5 \mathrm{~mm} \pm 0.05 \mathrm{~mm}$ ) was controlled using shims during heating (cure phase), providing a depth of the channels (copper + glue) of $2.5 \mathrm{~mm}$, giving them square shape.

As regards the cross-sectional dimensions of the channel (hydraulic diameter: $D_{h}=2.5 \mathrm{~mm}$ ), the existence of slug flow pattern cannot be assessed in microgravity conditions due to the infinite value of $B o_{c r i t}$, while on ground the latter is giving a critical diameter of $1.66 \mathrm{~mm}$ at $20^{\circ} \mathrm{C}$ for FC72. However, the previous visualizations of Mangini et al. [13] showed that the FC72 naturally distributes itself into slugs and plugs flow patterns in a $3 \mathrm{~mm}$ inner diameter cylindrical tube during microgravity phases. On ground conditions, the channel size leads to stratification, whatever the orientation.

Sixteen T-type thermocouples (TC) of $0.5 \mathrm{~mm}$ diameter (resolution: $\pm 0.5 \mathrm{~K}$ ) monitor the temperature of each section of the FPPHP (Fig. 1, right): six thermocouples were glued in six grooves on the back side of the evaporator $\left(T_{E V I}-T_{E V 6}\right)$; six others were inserted in six grooves on the back side of the condenser $\left(T_{C D 1}-T_{C D 6}\right)$; two thermocouples monitor the cooling fans inlet and 


\section{ACCEPTED MANUSCRIPT}

outlet air temperatures; one measures the air temperature inside the heater containment $\left(T_{h}\right)$ and the last one measures the aircraft ambient temperature $\left(T_{a m b}\right)$. A pressure sensor (GE PTX5076TA-A3-CA-HO-PS, 5 bars absolute, $\pm 200 \mathrm{~Pa}$ ) records the fluid pressure at the top of the condenser zone, with a sampling period of $10^{-6} \mathrm{~s}$. A $g$-sensor (DE-ACCM3D, $\pm 0.1 \mathrm{~g}$ ) is used to measure the gravity level variations during each parabolic flight. All signals have been recorded at $16 \mathrm{~Hz}$ sampling frequency (satisfying the Nyquist-Shannon criterion regarding the fluctuation frequencies of the wall temperatures, around $1 \mathrm{~Hz}$ maximum). Finally, a camera (XIMEA MG series Q3) is used together with a mirror, because of the confined low space, for the fluid flow pattern visualizations during the FPPHP operation (Fig 2).

The evaporator zone of the FPPHP is heated by a wire electrical heater (Thermocoax® Type ZEZAc10, $1 \mathrm{~mm}$ external diameter, $R=3.8 \Omega$ ) embedded in a serpentine groove machined in a copper plate of $10 \times 120 \mathrm{~mm}^{2}$ dimensions and $2 \mathrm{~mm}$ thick. The wire is connected to an electrical power supply (GWInstek® $36101, \pm 0.2 \mathrm{~V})$.

On the back side, the condenser section $\left(160 \times 120 \mathrm{~mm}^{2}\right)$ is embedded in an aluminum heat sink cooled by means of two air microprocessor cooling fans (Fig. 2, down). Both heater and heat sink interfaces are wedged with thermal grease (silicon heat transfer paste, $\lambda \approx 2.9 \mathrm{Wm}^{-1} \mathrm{~K}^{-1}$ ) to reduce thermal contact resistance. Finally, the heater/heat sink and PHP elements are surrounded by polytetrafluoroethylene plates and brackets to ensure double containment assembly for flight security purpose (Fig. 2). 


\section{ACCEPTED MANUSCRIPT}

Before being filled, the FPPHP was evacuated by means of an ultra-high vacuum system (ASM 142, Adixen by Pfeiffer Vaccum $\left.{ }^{\circledR}\right)$. The working fluid was degassed in a tank by heating/cooling cycles until reaching the mass value corresponding to the required filling ratio at ambient temperature.

Finally, the operative conditions for all the ground and microgravity tests are:

- Working fluid: FC72, filling ratio: $F R=50 \% \pm 2 \%$ at $20^{\circ} \mathrm{C}$;

- Heat power applied: from $20 \mathrm{~W}$ to $150 \mathrm{~W}$;

- Cold source: air at plane ambient temperature;

- Orientation: horizontal (ground tests only) and vertical bottom heated mode (BHM), normal to the aircraft lift.

\section{Results and discussion}

\section{Ground tests}

Although the current device can be only defined as a hydrid thermosyphon, since its channel dimension results into a fluid stratification on ground, and therefore it is not a proper FPPHP, the unusual hydraulic behavior observed for both configurations deserves to be described also for ground experiments, in order to understand the difference with the hyper- and microgravity experiments, where the gravity is also varying during the flights. Furthermore, on ground a thermal steady state condition for 1 -g level can be reached. 


\section{ACCEPTED MANUSCRIPT}

\section{FPPHP tests in vertical orientation}

In this specific configuration, long time tests have been run for at least one hour, to reach steady state conditions. The device is composed by different elements (electric wire, heater, PHP, aluminum heat sink, etc.) representing different thermal capacities connected in series by thermal resistances. The lighter elements (heater) heat up quite rapidly, converging asymptotically to the temperature trends of the heavier and farthest elements like the heat sink. Some changes in the fluid distribution happening randomly modify the conductance properties and hence the temperatures of the above mentioned components.

A typical long-time test run is presented in Fig. 3 for the temperature and pressure measurements, with $100 \mathrm{~W}$ heat power. Note that only the four most representative thermocouples have been plotted, in particular the two extreme temperatures for each zone $\left(T_{E V l}\right.$, and $T_{E V 3}$, being the coldest and hottest temperatures of the evaporator zone, and $T_{C D 1}$, and $T_{C D 3}$, being the coldest and the hottest temperatures of the condenser zone). Note that the curve colors and associated TCs remain the same for all the figures.

Fig. 4 shows a snapshot of a movie corresponding to the test of Fig. 3, at time indicated by the vertical dashed line. Only the six right hand-side U-turns are represented. The authors apologize for the poor quality of the still picture. Only the movie (in the supplementary online material: https://youtu.be/URhzEC_wqTY) gives a clearer and better image of the phenomena occurring inside the FPPHP. 


\section{ACCEPTED MANUSCRIPT}

When operated in vertical orientation, the 11 couples of channels, including their connecting lower U-turns, behave like boiling pools, each other interconnected by the top U-turns through which the vapor flows into the channels. Because of the presence of a slight transversal temperature gradient, as can be seen on evaporator temperatures in Fig. 3, due either to a better cooling of the lateral channels that locally improves the vapor condensation or to an "edge effect", which leads to higher temperature levels in the central zone of the evaporator. Because of the absence of any strong transversal redistribution and mixing phenomena, the liquid tends to migrate towards both sides of the FPPHP, leaving the central channels closer to dry-out (separation indicated by the red dashed line in Fig. 4). Some vapor always condenses in the upper part of the central channels, with annular condensation flowing down towards the evaporator, as can be hinted by the thin film bursting on left-hand side of Fig. 4. On the contrary the colder lateral channels tend to get filled by liquid, and lead to pure pool boiling with few bubbles rising along the channels. The two very lateral channels connected by the top horizontal channel (Fig. 1), due to their higher cooling capability, are completely flooded by liquid. Associated with its strong inertia, the liquid in these lateral channels levels down the possible fluid oscillations, practically disconnecting the two sides of the FPPHP through the top horizontal channel.

\section{FPPHP tests in horizontal orientation}

In horizontal position the FPPHP behavior is completely different. The liquid is no more segregated along the channels, and in such large channels, the capillary forces are not able to maintain the menisci contrasting the gravity effects; so, the liquid flows naturally with a mixed gravity and capillary assisted regime. On the other side, the gravity pressure drop transverse to 


\section{ACCEPTED MANUSCRIPT}

the channel is not strong enough to help the liquid flow back into the evaporator, when subjected to heat power and rising internal pressure. Consequently, the FPPHP tends to dry-out at much

lower heat power inputs than in vertical orientation. Fig. 5 presents the temperature and pressure measurements for the FPPHP tested in horizontal orientation, with increasing heat power levels up to $120 \mathrm{~W}$. Except for some oscillations noticed at the lower heat power level (here at $40 \mathrm{~W}$, where some temperature fluctuations are noticeable in Fig. 5), the FPPHP operates "dry", i.e. with all the liquid accumulated in the condenser region. This explains the smooth curves observed for higher heat powers. The FPPHP then operates practically in pure conductive mode. Fig. 6 shows an explanation of what was observed in the channels during horizontal operation. As mentioned above, as the evaporator zone tends to be dry-out, the liquid thus accumulates in the condenser region. However, in such large channels, gravity pressure head $\left(\Delta P_{g}=\rho_{l} g D \approx 42\right.$ $\mathrm{Pa})$, partially assisted by capillary pressure $\operatorname{drop}\left(\Delta P_{c} \leq \sigma /(D / 2) \approx 9 \mathrm{~Pa}\right)$ on the wettable channel surface, helps the liquid to flow back to the evaporator zone like an open-channel flow. The overall pressure head is not sufficient enough to bring the liquid FC72 to the evaporator end, since the mass flow rate from the stored liquid plugs leads to viscous pressure losses higher than the gravity and capillary ones on the overall length of every branch. The existence of an additional Marangoni effect is highly probable due to the temperature gradient from the condenser to the evaporator all along the branches.

Finally, note that, due to the square shape of the channel, a capillary pumping in the corners builds a liquid film which is flowing in the vapor phase direction, i.e. to the evaporator. In general the presence of liquid close to the evaporator zone leads to improved thermal performance with respect to those of the classical dry-out FPPHP in smaller channels with a 


\section{ACCEPTED MANUSCRIPT}

sharp liquid/vapor frontier imposed only by capillary forces [16]. At low heat powers (i.e. with lower evaporation rate), low frequency temperature and pressure oscillations are observed in the FPPHP proving the slow dry-out and the presence of re-wetting phenomena. In horizontal position, the vapor from the evaporator region moves above the stratified liquid and goes to condenser, thus forming a further small pressure head which tends to slowly push back the liquid towards the evaporator. Such oscillations fade away with increasing heat power.

\section{Parabolic flight campaign tests}

A parabolic flight campaign consists of three days of tests during which 31 parabola trajectories are carried out every day. Each parabola has a period of $22 \mathrm{~s}$ of microgravity (with an average

gravity normal to the aircraft floor of $0.1 \mathrm{~ms}^{-2}=1 / 100 g$, according to Novespace's database [19]) preceded and followed by two periods of $20 \mathrm{~s}$ of hypergravity (at approximately $1.8 \mathrm{~g}$ ).

During these tests, the FPPHP has been tested only in BHM, varying the heat power from $20 \mathrm{~W}$ to a maximum value of $150 \mathrm{~W}$, with constant levels of heat power during each series of five consecutive parabolas. The following results are representative of the main thermal and hydraulic behavior observed during the parabolic flight campaign tests. It is important to consider that all the measures in hyper- and micro-gravity conditions are not in a steady state, due to the high thermal inertia of the FPPHP. Figs. 7 to 9 show a sample of the temperature and pressure profiles with three values of heat power (50, 90 and $120 \mathrm{~W}$ for Figs. 7, 8 and 9, respectively) applied on a set of five successive parabolas. The first observation is that, during microgravity phases, the temperatures rise in the evaporator zone and decrease in the condenser zone. Furthermore, the evaporator temperatures are subject to some oscillations, as well as the pressure signal during this period. A change in the 


\section{ACCEPTED MANUSCRIPT}

flow pattern occurs and leads to performance degradation, compared to pool boiling or annular flow pattern in normal and hypergravity. Note that the hypergravity phases have practically no influence on the temperature and pressure values, with only a slightly better performance, as already observed in [12]. Increasing gravity eventually improves heat transfer in BHM: on one hand by increasing vapor bubbles velocities in vertical branches subject to pool boiling; on the other hand, by increasing the liquid film velocity (therefore decreasing its thickness) in dry branches subject to annular condensation.

Except for the first curve at $50 \mathrm{~W}$ (Fig. 7), the temperature response under normal and hypergravity presents a feature of repeatability despite the change of fluid distribution resulting after the microgravity phases. A change in the temperature profiles occurs after the third parabola of Fig. 7, accompanied by a change of the hottest TC between $T_{E V 4}$ and $T_{E V 3}$ : all the temperatures tends to get closer at the evaporator, while simultaneously they slightly increase at the condenser. In fact, the flow pattern occurring in microgravity phase tends to homogenize the fluid distribution inside the whole PHP, before returning into a segregated state in normal gravity for which the central channels of the FPPHP are again partially filled with the liquid phase. To fully understand the phenomena occurring in microgravity, two experimental cases are presented, one at low heat power ( $30 \mathrm{~W}$, Figs. 10 and 11), and the other at high heat power (150 W, Figs. 12 and 13). Fig. 10 plots temperatures/pressure curves together with acceleration in function of time for two parabolas. The microgravity tends to increase the evaporator temperatures, even if irregularly, and not for all the TCs at the same time (see the second parabola in Fig. 10). Hence, there are periods of start-and-stop operation, which are scarcely reproducible. Fig. 11 presents a snapshot of a movie recorded during second parabola of Fig. 10, 


\section{ACCEPTED MANUSCRIPT}

at time indicated by the vertical dashed line (see supplementary online material:

https://youtu.be/jOdkzr-GY4w). Like in Fig. 4, only the six right hand-side U-turns are

represented. The most important information here is that, during microgravity, the flow pattern turns into slug flow, with consecutive liquid plugs and vapor bubbles invading the entire internal transverse section of the channels, as in Mangini et al. [13] with their $3 \mathrm{~mm}$ inner diameter tubular PHP tested during ESA $61^{\text {th }}$ parabolic flight campaign.

Despite the poor quality of the still picture of Fig. 11, one can distinguish multiple bubble trains in many channels. With no gravity forces, even low capillary forces are strong enough to maintain liquid plugs between two vapor bubbles. Otherwise, due to very low capillary pressures and low viscous pressure losses (both linked to the high hydraulic diameter of this FPPHP), the liquid plugs move very impulsively, the menisci break and the flow pattern changes into a more chaotic condition, such as a bubbly flow.

This results in two major behaviors in microgravity BHM for such a large diameter FPPHP: first, the fluid tends spontaneously to a dry-out at the evaporator zone due to higher and more homogeneous vapor pressures in the channels in this zone; this process is well described in [20]; second, isolated liquid plugs can move even under the influence of smaller pressure variations. Such liquid plugs may flow through the hot evaporator zone, leading to a strong evaporation and increasing the local pressure. This results in triggering the slug flow pattern motion in all FPPHP channels, thus temporarily improving the overall heat transfer, hence diminishing the evaporator temperatures, until the following decrease of the fluid motion causes a dry-out, and so on. Note also that some long liquid plugs crossing hot zones of the evaporator were subject to multiple 


\section{ACCEPTED MANUSCRIPT}

consecutive boiling, as can be seen in Fig. 11 (and supplementary online material:

https://youtu.be/jOdkzr-GY4w).

Fig. 12 presents temperature/pressure evolution together with the acceleration for a heat power of $150 \mathrm{~W}$ : as mentioned before, the microgravity phase is accompanied by a strong and rapid increase of the evaporator temperatures, during which fluctuations are clearly distinguishable.

For all tested cases, an analysis of the related videos showed that the fluctuations were associated to periods of "start-and-stop", the "stops" corresponding to dry-out of the evaporator, and the "starts" to triggering of the overall motion of the slugs. To illustrate this phenomenon, Fig. 13 presents a snapshot of a movie recorded during the second parabola in Fig. 12, during a dry-out phase just before an overall massive motion (see supplementary online material:

https://youtu.be/vh84wa5JB2I). A $15 \mathrm{~mm}$ long liquid plug down the left-end channel shifts to the evaporator (yellow arrow). Once reaching the hot evaporator surface, a sudden evaporation appears and leads to a local pressure increase, which initiates the overall motion again, as mentioned before. However, dry-out and dynamic phases appear here with higher frequency than for lower heat powers.

In conclusion, a slug flow pattern is possible under microgravity in geometries where only a stratified two-phase flow is possible on ground. In order to illustrate such repeatable phenomenon, a movie was recorded during the $64^{\text {th }}$ ESA Parabolic Flight Campaign, when various configurations of FPPHP have been further tested. Fig. 14 shows successive images of a FPPHP with the same geometry with respect to the one tested before (channel dimension $2.5 \mathrm{x}$ $2.5 \mathrm{~mm}^{2}$, evaporator length $10 \mathrm{~mm}$, overall width $124 \mathrm{~mm}$, length $204 \mathrm{~mm}$ and thickness $2.5 \mathrm{~mm}$ ) except for the condenser length $(100 \mathrm{~mm}$ instead of $160 \mathrm{~mm})$. The video was recorded 


\section{ACCEPTED MANUSCRIPT}

for $100 \mathrm{~W}$ heat power. Six successive pictures, with a time step of $0.5 \mathrm{~s}$, are shown with an isolated liquid plug (about $25 \mathrm{~mm}$ long) which progressively moves away from another even longer liquid plug situated on its left, both being initially separated by a small vapor bubble. Gradually as the plug enters in the hot and dry evaporator zone on the right hand side, it undergoes a rather significant and rapid evaporation which triggers a global fluid motion. Such peculiar behavior has been observed only under microgravity conditions (and specifically with a low surface tension fluid), and this differentiates the FPPHP operation under normal gravity conditions.

To conclude also on the expected use of pulsating heat pipes for spacecraft applications, even if their thermal performances are obviously better in ground configuration (under a vertical bottom heated mode), it has been found that even a simple FPPHP prototype can successfully operate under microgravity conditions at least for fluids having low surface tensions. Henceforth, advanced PHP-based thermal systems for space applications can be likely designed considering also fluids with higher surface tensions (such as alcohols, water, etc.), for which, since the phase separation would be for vapor velocities higher than those of FC72, the evaporator dry-out occurs at higher heat loads. This will open the use of PHPs (capillary only in space) for heat powers and fluxes not attainable with the usual grooved and loop heat pipes, with the further advantages of a reduced complexity, low cost, low weight and even the possibility to insert flexible parts. Further experimental tests needs to be carried out to validate these last assumptions. 


\section{ACCEPTED MANUSCRIPT}

\section{Conclusions}

An experimental test on ESA Parabolic Flights has been carried out for a Flat Plate Pulsating Heat Pipe made by a grooved copper plate covered by a glass layer, allowing visualization of the flow patterns for the different gravity and heat power conditions. The working fluid is a refrigerant (FC72) filling the channel at 50\% FR. Specifically, the present FPPHP has a hydraulic diameter higher than the so-called static capillary limit, linked to the Bond number. Nevertheless in microgravity conditions, such capillary diameter ceases to have a physical meaning, and inertial and viscous forces become predominant. Since in microgravity the diameter threshold for slug-plug hydraulic regime can be higher than the static capillary limit in gravity conditions, a FPPHP with a larger diameter shows better performances and higher power dissipation just in microgravity conditions. On the other side, high velocity oscillations are more probable with the consequent break-up of the liquid menisci, i.e. the present FPPHP displays a lower heat power limit for dry-out. The experimental test confirms that, even if on ground an evident fluid stratification is present, in microgravity the flow rapidly turns into slug-plug flow, with liquid slugs invading the entire internal transverse section of the channels. The pressure pulses help in maintaining the internal fluid oscillation. To notice, these tests have also enabled to highlight the role of local instabilities inducing mass and heat transfers inside the FPPHP, largely helped by the fact that the motion of liquid slugs causes very low pressure losses, being such experimental evidence impossible to observe under normal gravity. 


\section{ACCEPTED MANUSCRIPT}

\section{Acknowledgements}

The authors acknowledge the financial support of the Italian Space Agency through the ASIAO2009 DOLFIN-II within the ESA $62^{\text {th }}$ parabolic flight campaign. This work was partially supported also by ESA MAP project INWIP "Innovative Wickless Heat Pipe Systems for Ground and Space Applications". Special thanks must be given to NOVESPACE team in Bordeaux for their assistance, to V. Pletser, Dr. O. Minster and Dr. B. Toth from ESA. Scientific discussions with Prof. S. Filippeschi and Dr. M. Mameli, University of Pisa, have been quite useful to carry out the present research. Lastly, let us not forget Dr. A. Piteau, Y. Thomas and JC. Fraudeau from P' Institut for their great technical support. 


\section{ACCEPTED MANUSCRIPT}

\section{Nomenclature}

$\begin{array}{ll}\text { BHM } & \text { Bottom Heated Mode } \\ \text { Bo } & \text { Bond number [-] } \\ D & \text { Diameter, dimension [m] } \\ \text { FPPHP } & \text { Flat Plate Pulsating Heat Pipe } \\ F R & \text { Feeling ratio [\%] } \\ g & \text { Gravity acceleration }\left[\mathrm{m} \mathrm{s}^{-2}\right] \\ P & \text { Pressure [Pa] } \\ P H P & \text { Pulsating Heat Pipe } \\ Q & \text { Heat power }[\mathrm{W}] \\ R & \text { Electrical resistance }[\Omega] \\ t & \text { Time [s] } \\ T & \text { Temperature }\left[{ }^{\circ} \mathrm{C}\right] \\ T C & \text { Thermocouple } \\ v & \left.\text { Velocity [m s }{ }^{-1}\right] \\ W e & \text { Weber number }[-]\end{array}$

\section{Greek symbols}

$\begin{array}{ll}\lambda & \text { Thermal conductivity }\left[\mathrm{W} \mathrm{m}^{-1} \mathrm{~K}^{-1}\right] \\ \rho & \text { Density }\left[\mathrm{kg} \mathrm{m}^{-3}\right] \\ \sigma & \text { Surface tension }\left[\mathrm{N} \mathrm{m}^{-1}\right]\end{array}$




\section{ACCEPTED MANUSCRIPT}

$\begin{array}{ll}\text { Subscripts } & \\ \text { amb } & \text { ambient air } \\ \text { c } & \text { capillary } \\ \text { CD } & \text { condenser zone } \\ \text { crit } & \text { critical } \\ \text { EV } & \text { evaporator zone } \\ \text { h } & \text { hydraulic/heater } \\ \text { g } & \text { gravity } \\ \text { l } & \text { liquid } \\ \text { v } & \text { vapor }\end{array}$




\section{ACCEPTED MANUSCRIPT}

\section{References}

[1] Tong, B., Wong, T. and Ooi, K., Closed-loop pulsating heat pipe, Applied Thermal Engineering, Vol. 21, pp. 1845-1862, 2001.

[2] Khandekar, S., Charoensawan, P., Groll, M. and Terdtoon, P., Closed loop pulsating heat pipes, part B: visualization and semi-empirical modeling, Applied Thermal Engineering, Vol. 23, pp. 2021-2033, 2003.

[3] Liu, S., Li, J., Dong, X. and Chen, H., Experimental study of flow patterns and improved configurations for pulsating heat pipes, Journal of Thermal Sciences, Vol. 16, pp. 56-62, 2007.

[4] Khandekar, S., Dollinger, N. and Groll, M., Understanding operational regimes of closed pulsating heat pipes: an experimental study, Applied Thermal Engineering, Vol. 23, pp. 707-719, 2003.

[5] Charoensawan, P., Khandekar, S., Groll, M. and Terdtoon, P., Closed loop pulsating heat pipes, part A: parametric experimental investigations, Applied Thermal Engineering, Vol. 23, pp. 2009-2020, 2003.

[6] Zhang, Y. and Faghri, A., Advances and unsolved issues in pulsating heat pipes, Heat Transfer Engineering, Vol. 29, pp. 20-44, 2008.

[7] Mameli, M., Marengo, M., Zinna, S., Thermal simulation of a pulsating heat pipes: effects of different liquid properties on a simple geometry, Heat Transfer Engineering, Vol. 33, pp. 1177-1187, 2012.

[8] Gu, J., Kawaji, M. and Futamata, R., Microgravity performances of micro pulsating heat pipe, Microgravity Science and Technology, Vol. 16, pp. 181-185, 2005. 


\section{ACCEPTED MANUSCRIPT}

[9] Mameli, M., Araneo, L., Filippeschi, S., Marelli, L., Testa, R. and Marengo, M., Thermal response of a closed loop pulsating heat pipe under a varying gravity force, International Journal of Thermal Sciences, Vol. 80, pp. 11-22, 2014.

[10] Iwata, N., Ogawa, H. and Miyazaki, Y., Visualization of Oscillating Heat Pipe under microgravity, Proceedings of $17^{\text {th }}$ International Heat Pipe Conference, October 13-17, Kanpur, India, pp. 425-431, 2013.

[11] Iwata, N., Ogawa, H., Miyazaki, Y., Kawai, H., Fukuda, S., Innovative thermal design satellite with networked variable conductance oscillating heat pipes, Proceedings of Joint $18^{\text {th }}$ IHPC and $12^{\text {th }}$ IHPS, June 12-16, Jeju, Korea, 8 pages, 2016.

[12] Ayel, V., Araneo, L., Scalambra, A., Mameli, M., Romestant, C., Piteau, A., Marengo, M., Filippeschi, S. and Bertin, Y., Experimental study of a closed loop flat plate pulsating heat pipe under a varying gravity force, International Journal of Thermal Sciences, Vol. 96, pp.23-34, 2015.

[13] Mangini, D., Mameli, M., Georgoulas, A., Araneo, L., Filippeschi, S. and Marengo, M., A pulsating heat pipe for space applications: Ground and microgravity experiments, International Journal of Thermal Sciences, Vol. 95, pp. 53-63, 2015.

[14] Mangini, D., Mameli, M., Fioriti, D., Filippeschi, S., Araneo, L., and Marengo, M., Hybrid pulsating heat pipe for space applications with non-uniform heating patterns: ground and microgravity experiments, Proceedings of Joint $18^{\text {th }}$ IHPC and $12^{\text {th }}$ IHPS, June $12-16$, Jeju, Korea, 8 pages, 2016.

[15] Khandekar, S., Thermofluid dynamic study of flat-plate closed-loop pulsating heat pipes, Microscale Thermal Engineering, Vol. 6, pp. 303-317, 2003. 


\section{ACCEPTED MANUSCRIPT}

[16] Ayel, V., Romestant, C., Bertin, Y., Manno, V. and Filippeschi, S., Visualization of flow patterns in flat plate pulsating heat pipe: influence of hydraulic behaviour on thermal performances, Proceedings of $17^{\text {th }}$ International Heat Pipe Conference, October 13-17, Kanpur, India, pp. 377-384, 2013.

[17] Khandekar, S., Schneider, M., Schäfer, P., Kulenovic, R., Groll, M., Thermofluid dynamic study of flat-plate closed loop pulsating heat pipes, Microscale Thermophysical Engineering, Vol. 6, pp. 303-317, 2002.

[18] Yang, H., Khandekar, S., Groll, M., Performances characteristics of pulsating heat pipes as integral thermal spreaders, International Journal of Thermal Sciences, Vol. 48, pp. 815-824, 2009.

[19] Novespace A300 Zero-g Rules and Guidelines, April, $7^{\text {th }}$ 2009, RG-2009-2, NOVESPACE, 15, rue des Halles, 75001 Paris, France.

[20] Soponpongpipat, N., Sakulchangsatjaati, P., Kalluang-Lue, N. and Terdtoon, P., Investigation of the startup condition of a closed-loop oscillating heat pipe, Heat Transfer Engineering, Vol. 30, pp. 626-642, 2009. 


\section{ACCEPTED MANUSCRIPT}

\section{List of figure captions}

Fig. 1. Front side of the FPPHP with heater and cold source positions (left), and TC positions on the back side (right)

Fig. 2. FPPHP assembly: front side photograph (top); schematic top views of PHP, mirror and camera (left/down) and back side with radiator fins and fans (right/down)

Fig. 3. Transient temperature/pressure responses of the FPPHP to a long time test at $Q=100 \mathrm{~W}$ (ground tests, vertical orientation)

Fig. 4. Corresponding characteristic flow pattern in the right-half FPPHP at time indicated in Fig. 3 (ground tests, vertical orientation, $Q=100 \mathrm{~W}$ )

Fig. 5. Transient temperature response of the FPPHP to increasing levels of heat power (ground tests, horizontal orientation)

Fig. 6. Flow pattern in horizontal orientation in terrestrial gravity

Fig. 7. Transient temperatures and pressure during a series of 5 parabolas at $Q=50 \mathrm{~W}$ Fig. 8. Transient temperatures and pressure during a series of 5 parabolas at $Q=90 \mathrm{~W}$ Fig. 9. Transient temperatures and pressure during a series of 5 parabolas at $Q=150 \mathrm{~W}$ Fig. 10. Transient temperatures and pressure for two successive parabolas at $Q=30 \mathrm{~W}$ Fig. 11. Corresponding flow patterns in the right-half of the FPPHP surface during microgravity conditions at time indicated by dashed line of Fig. $8(Q=30 \mathrm{~W})$

Fig. 12. Transient temperatures and pressure for two successive parabolas at $Q=150 \mathrm{~W}$ Fig. 13. Corresponding flow pattern in the right-half FPPHP during microgravity conditions at time indicated by dashed line of Fig. $10(Q=150 \mathrm{~W})$ 


\section{ACCEPTED MANUSCRIPT}

Fig. 14. Sequence of macro images of an isolated liquid plug flowing towards the evaporator and subject to evaporation (parabolic flight, $Q=100 \mathrm{~W}$ ) 


\section{ACCEPTED MANUSCRIPT}
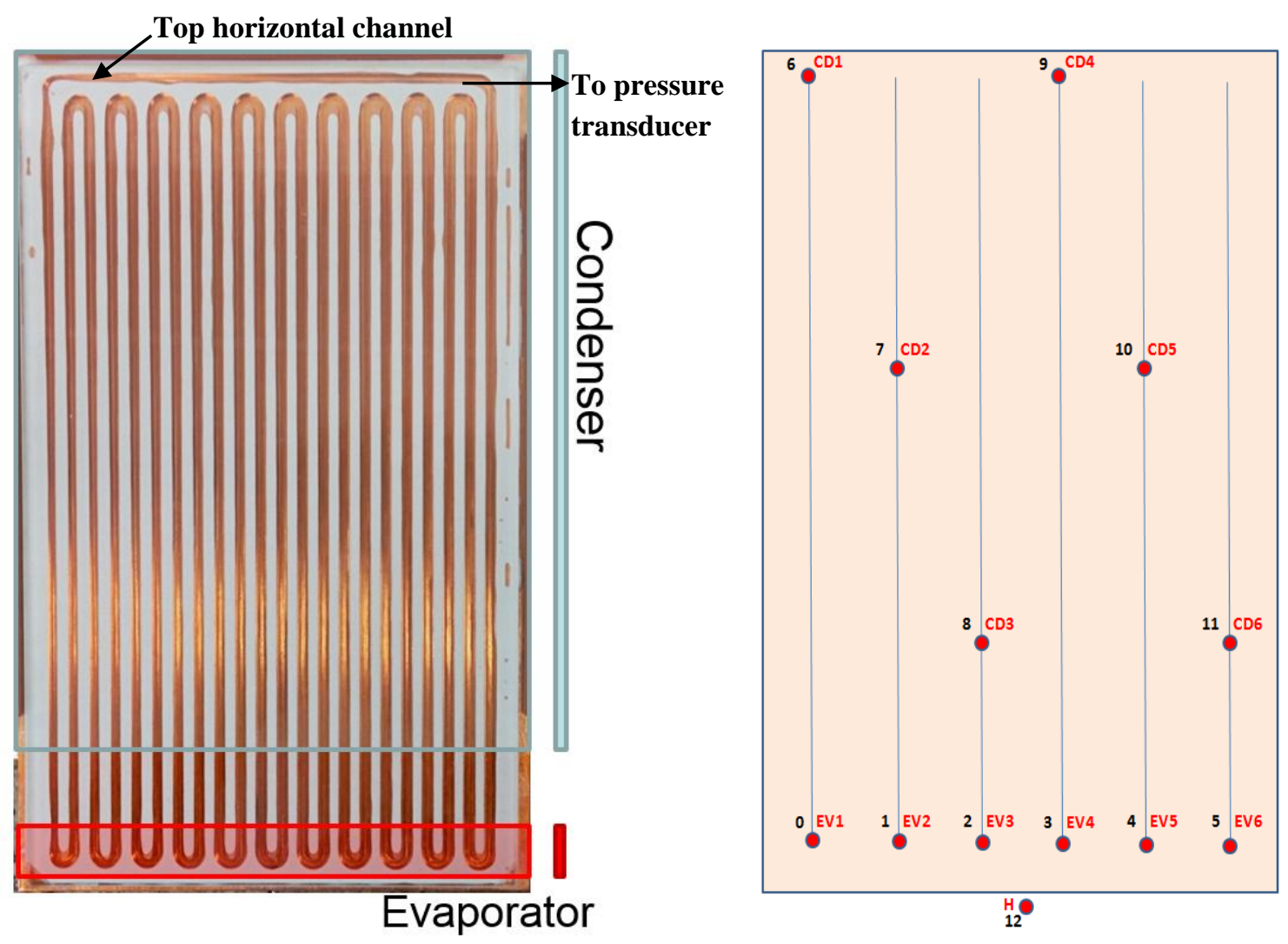

Fig. 1. Front side of the FPPHP with heater and cold source positions (left), and TC positions on the back side (right) 


\section{ACCEPTED MANUSCRIPT}
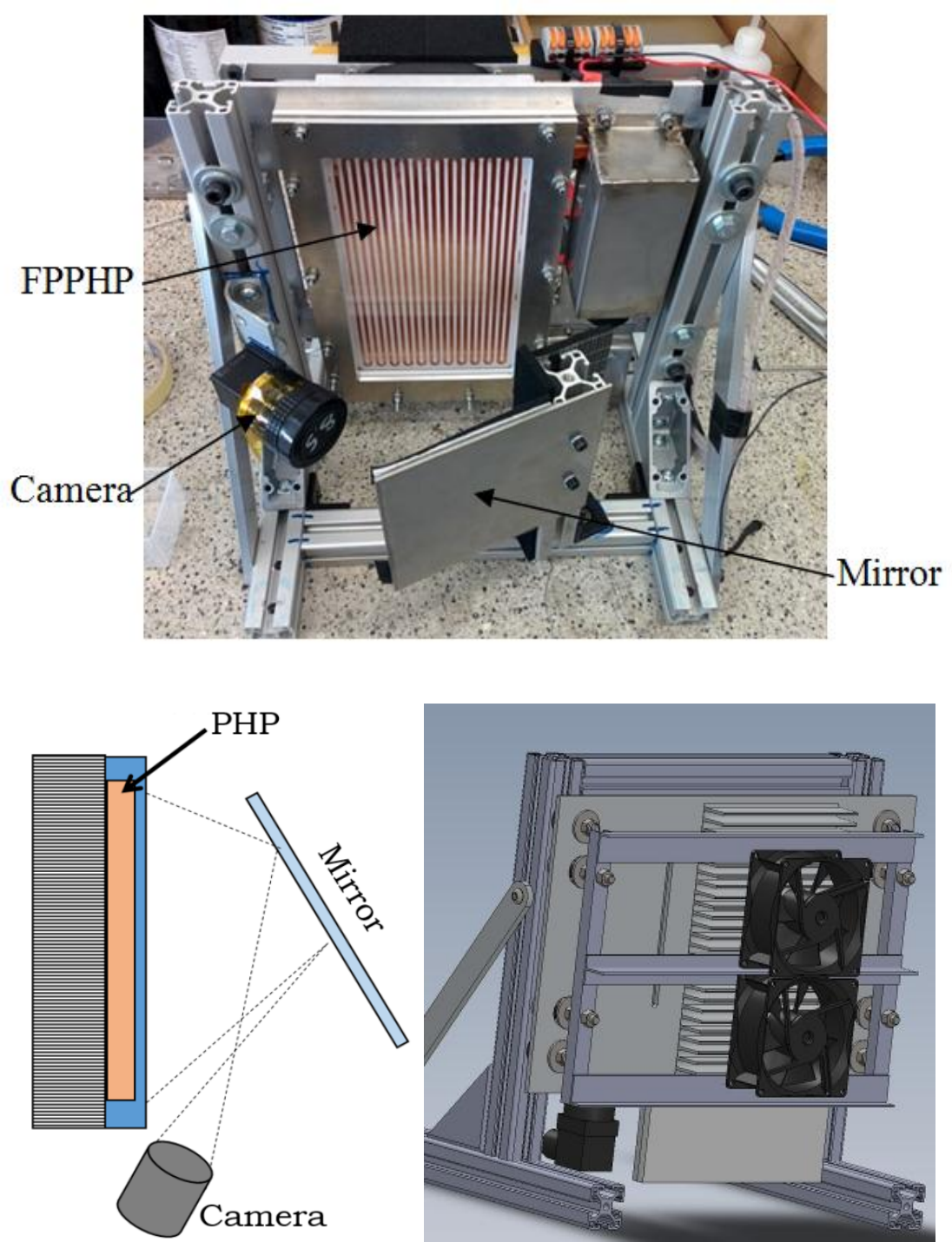

Fig. 2. FPPHP assembly: front side photograph (top); schematic top views of PHP, mirror and camera (left/down) and back side with radiator fins and fans (right/down) 


\section{ACCEPTED MANUSCRIPT}

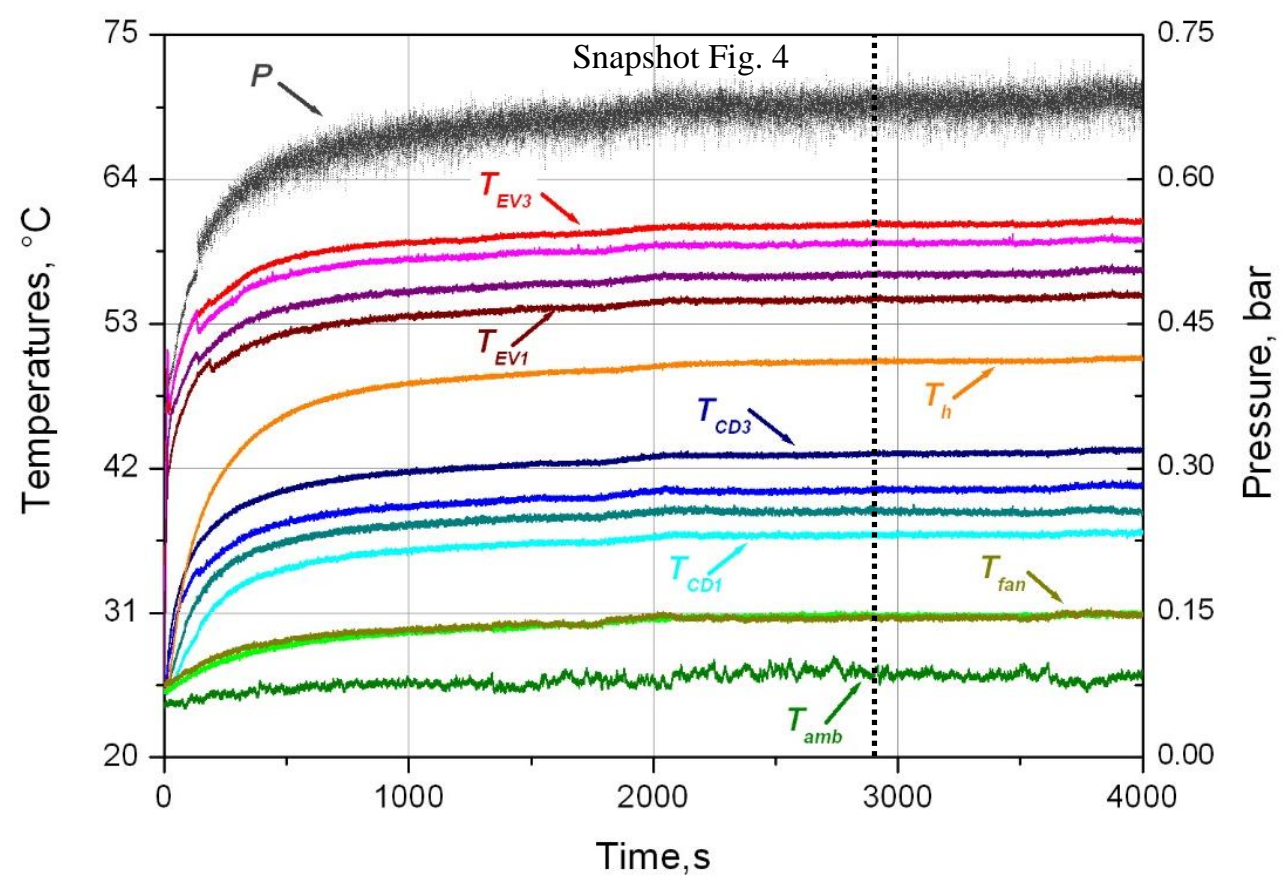

Fig. 3. Transient temperature/pressure responses of the FPPHP to a long time test at $Q=100 \mathrm{~W}$ (ground tests, vertical orientation) 


\section{ACCEPTED MANUSCRIPT}

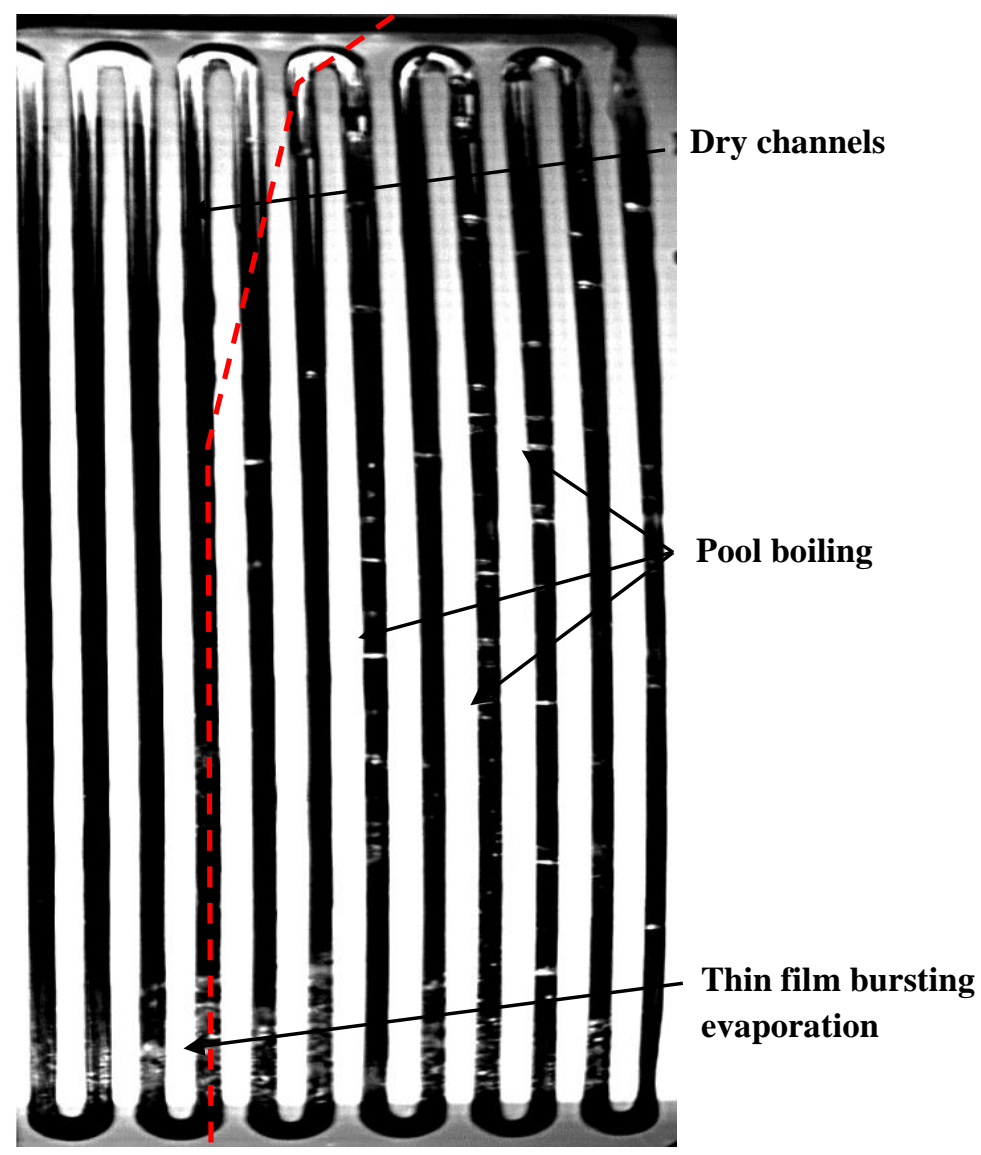

Fig. 4. Corresponding characteristic flow pattern in the right-half FPPHP at time indicated in Fig. 3 (ground tests, vertical orientation, $Q=100 \mathrm{~W}$ ) 


\section{ACCEPTED MANUSCRIPT}

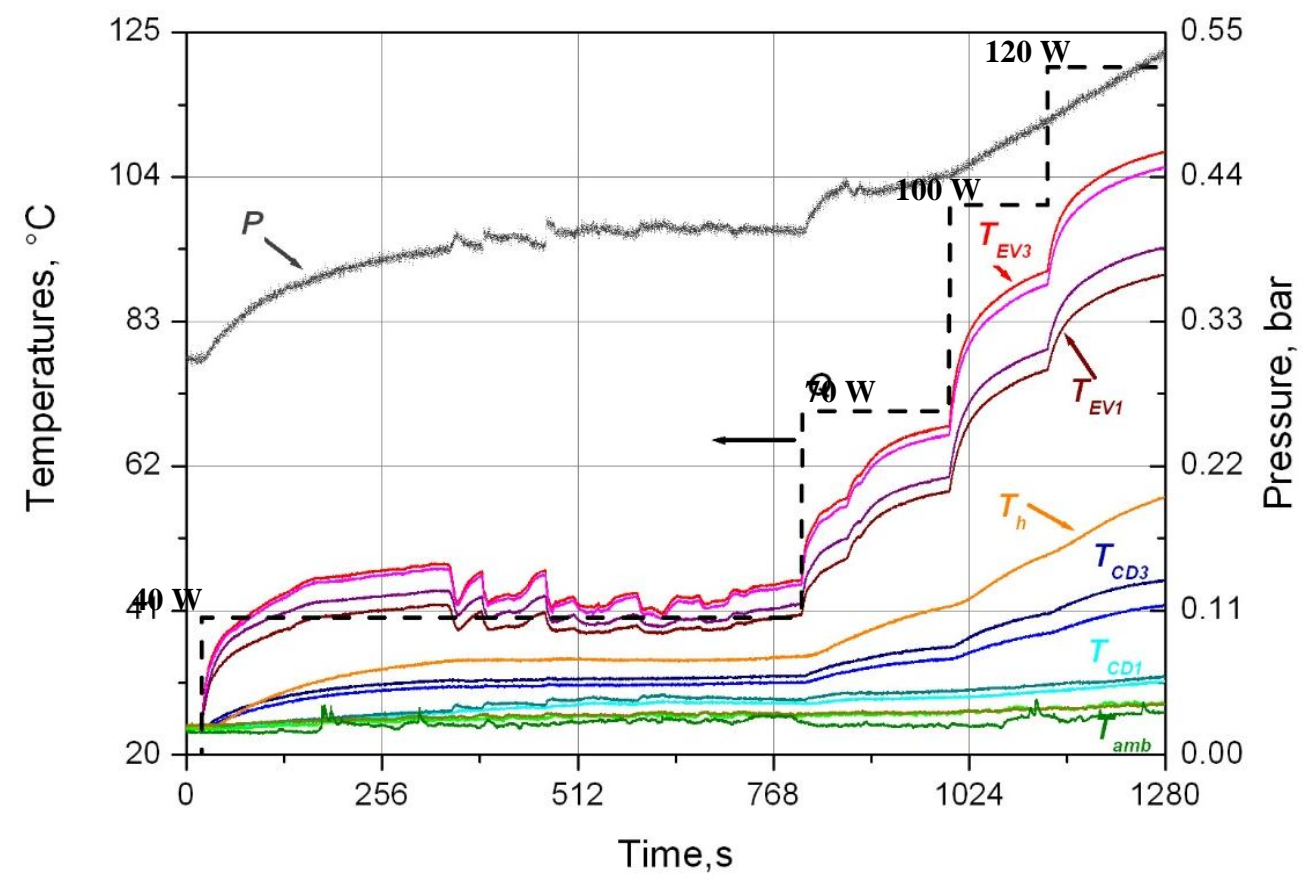

Fig. 5. Transient temperature response of the FPPHP to increasing levels of heat power (ground tests, horizontal orientation). 


\section{ACCEPTED MANUSCRIPT}

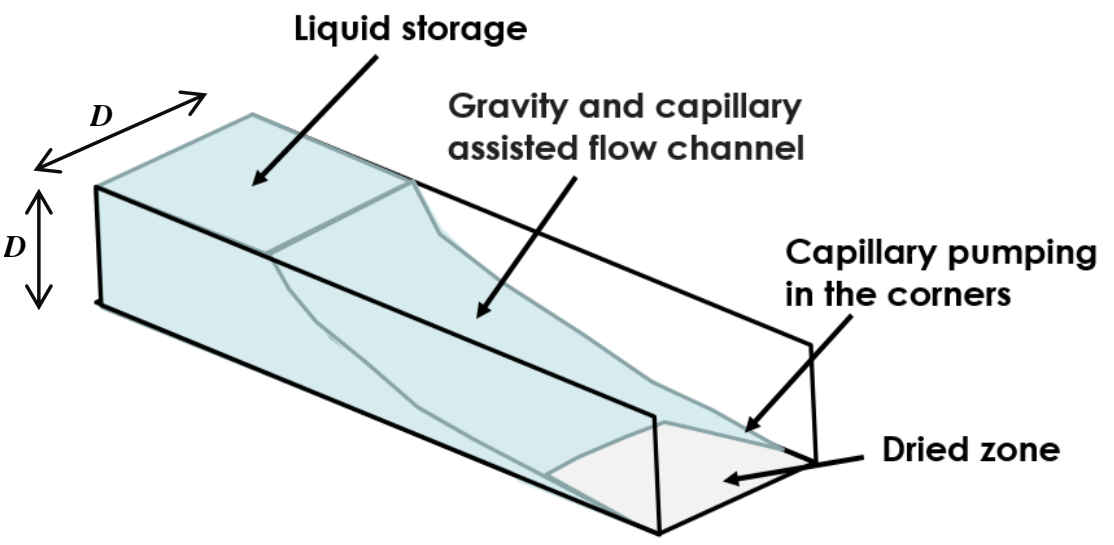

Fig. 6. Flow pattern in horizontal orientation in terrestrial gravity 


\section{ACCEPTED MANUSCRIPT}

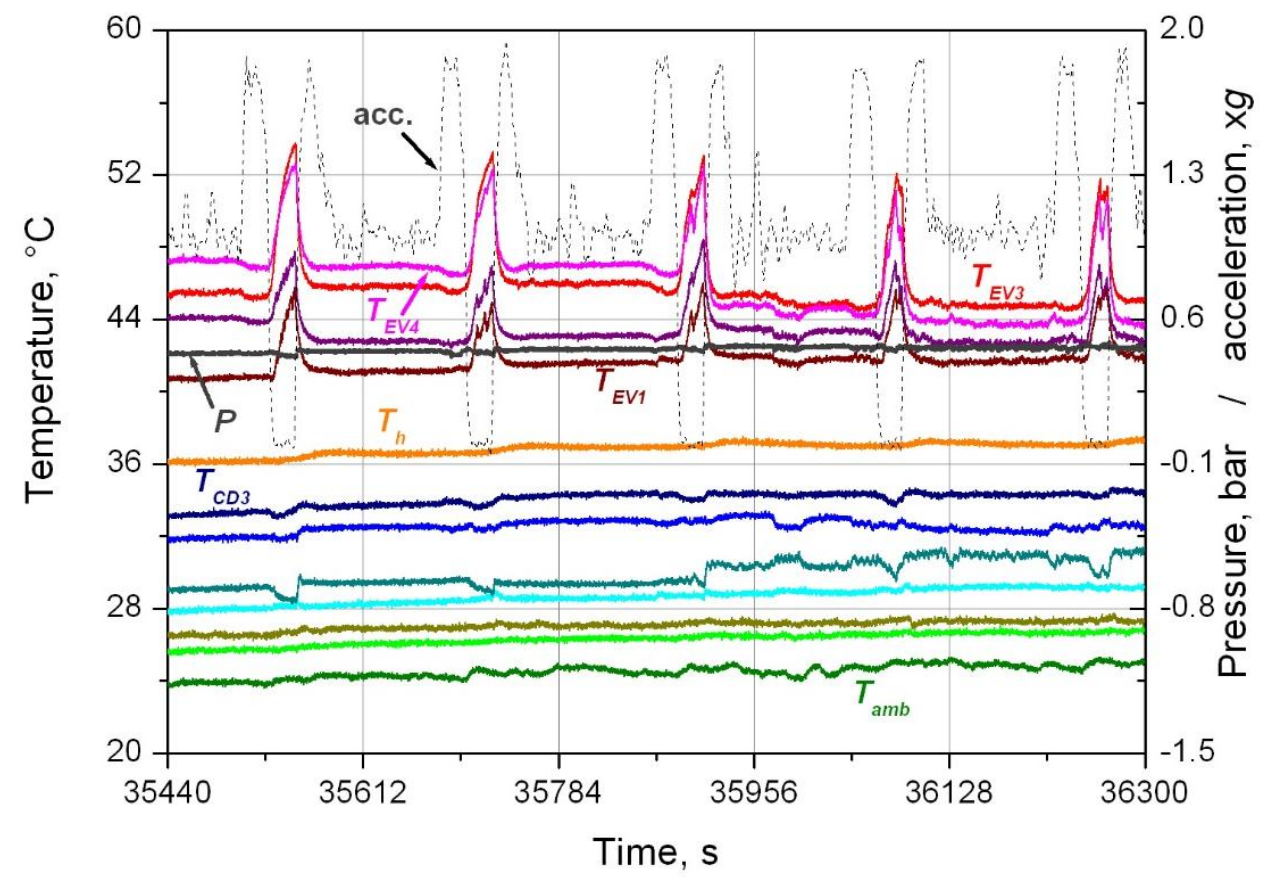

Fig. 7. Transient temperatures and pressure during a series of 5 parabolas at $Q=50 \mathrm{~W}$ 


\section{ACCEPTED MANUSCRIPT}

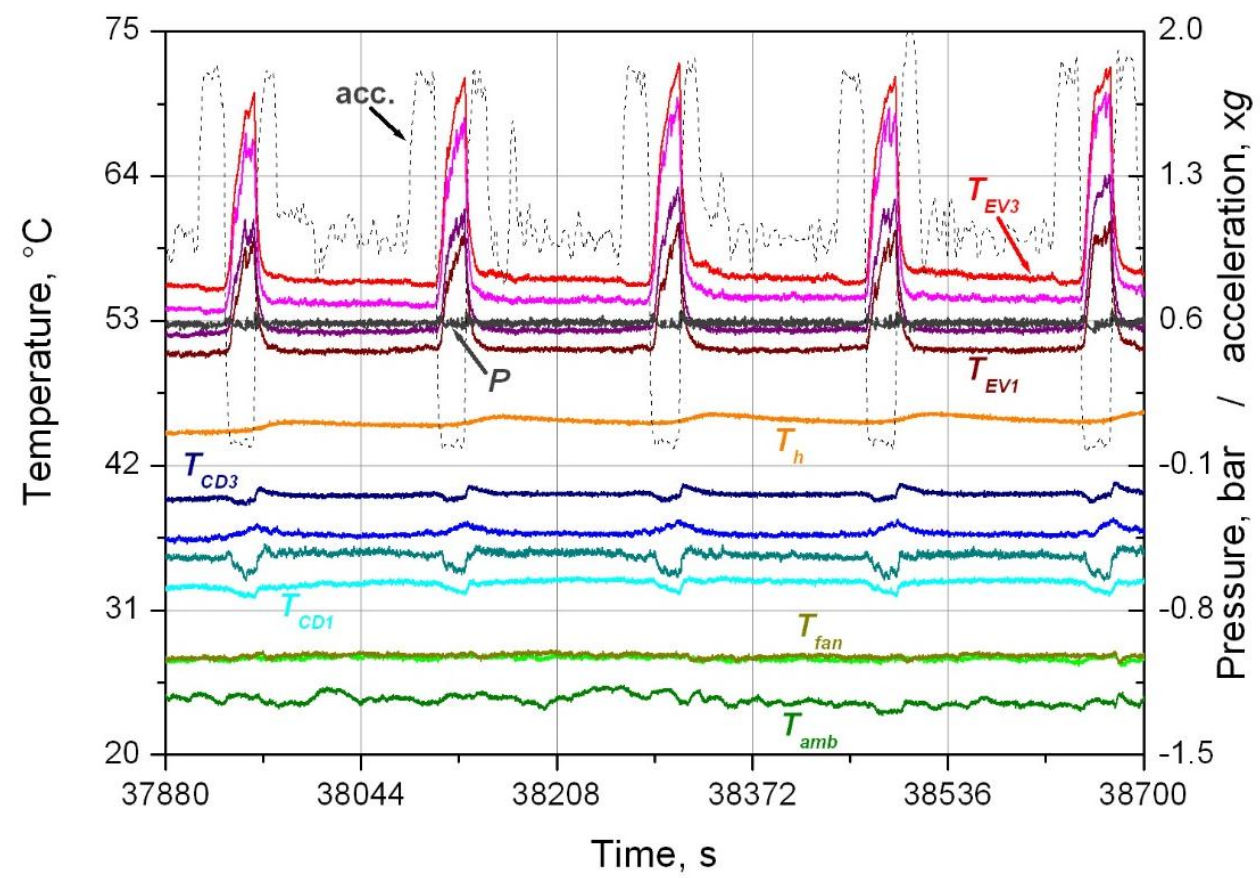

Fig. 8. Transient temperatures and pressure during a series of 5 parabolas at $Q=90 \mathrm{~W}$ 


\section{ACCEPTED MANUSCRIPT}

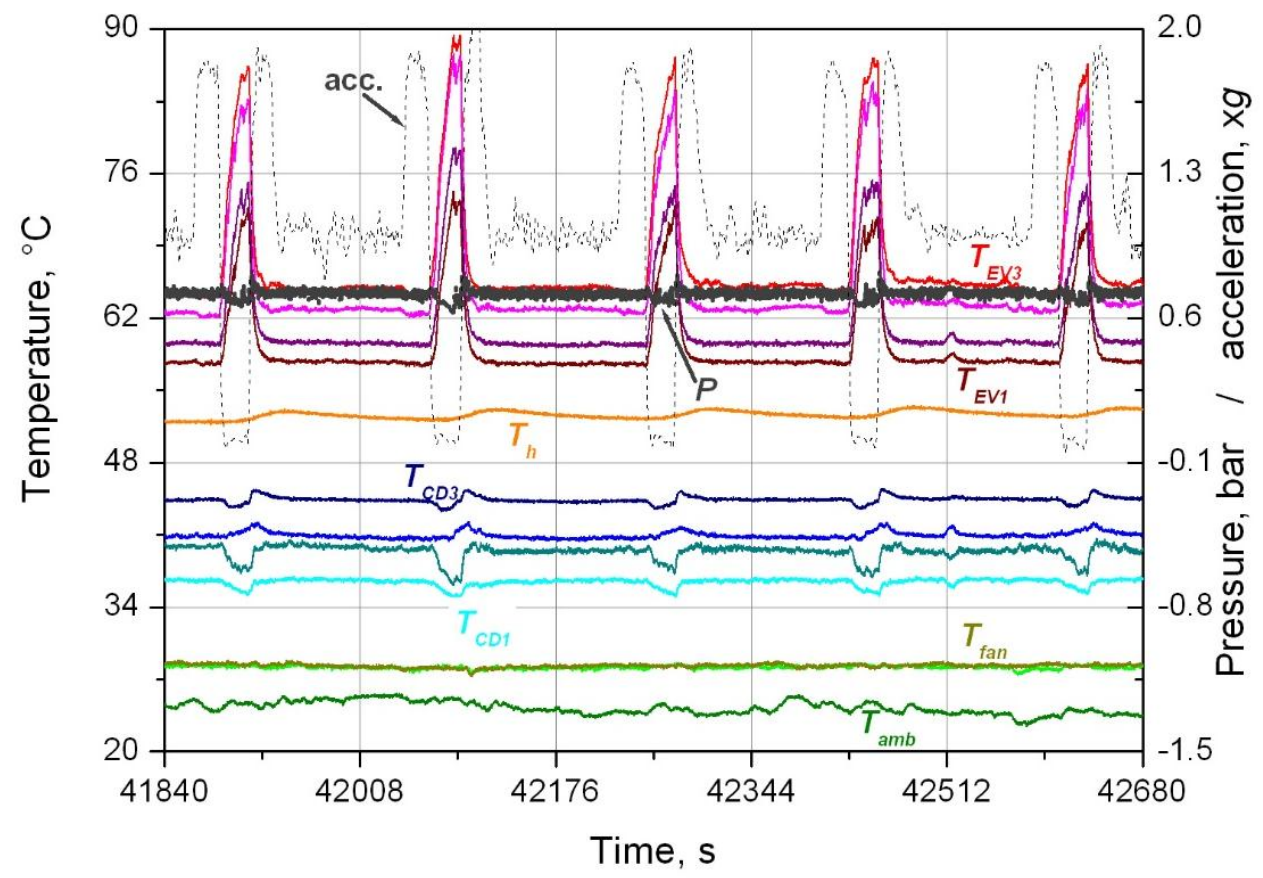

Fig. 9. Transient temperatures and pressure during a series of 5 parabolas at $Q=120 \mathrm{~W}$ 


\section{ACCEPTED MANUSCRIPT}

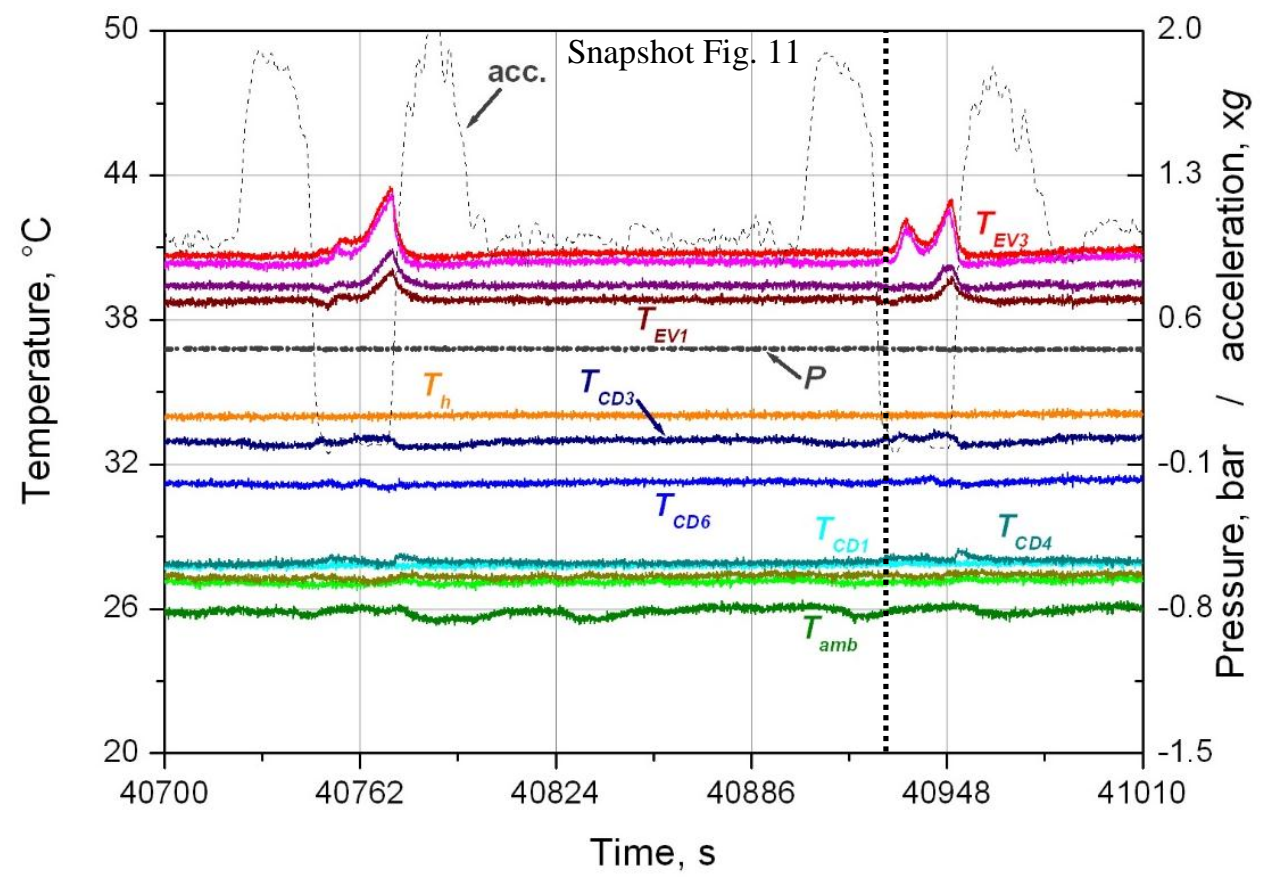

Fig. 10. Transient temperatures and pressure for two successive parabolas at $Q=30 \mathrm{~W}$ 


\section{ACCEPTED MANUSCRIPT}

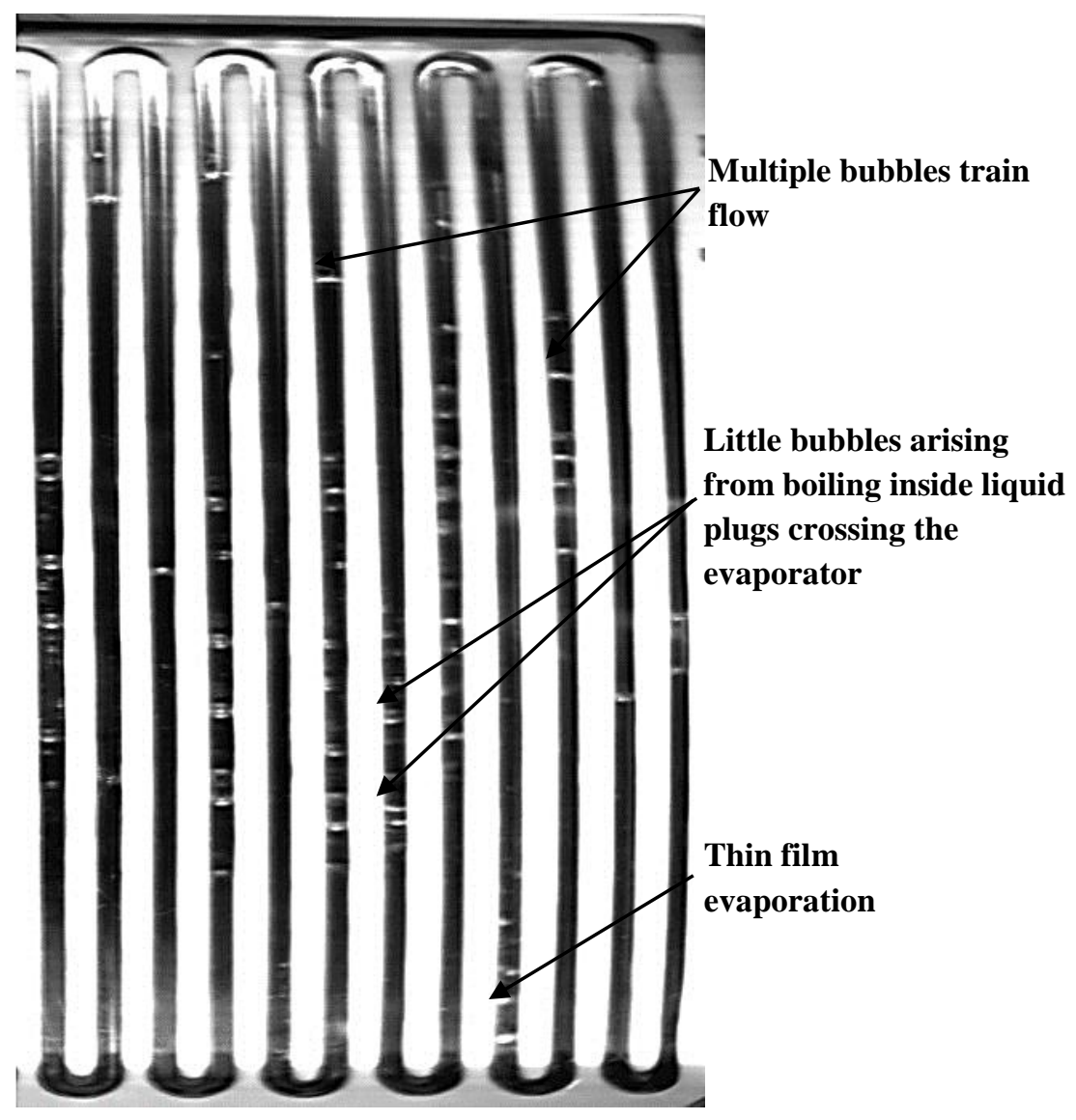

Fig. 11. Corresponding flow patterns in the right-half of the FPPHP surface during microgravity conditions at time indicated by dashed line of Fig. $10(Q=30 \mathrm{~W})$ 


\section{ACCEPTED MANUSCRIPT}

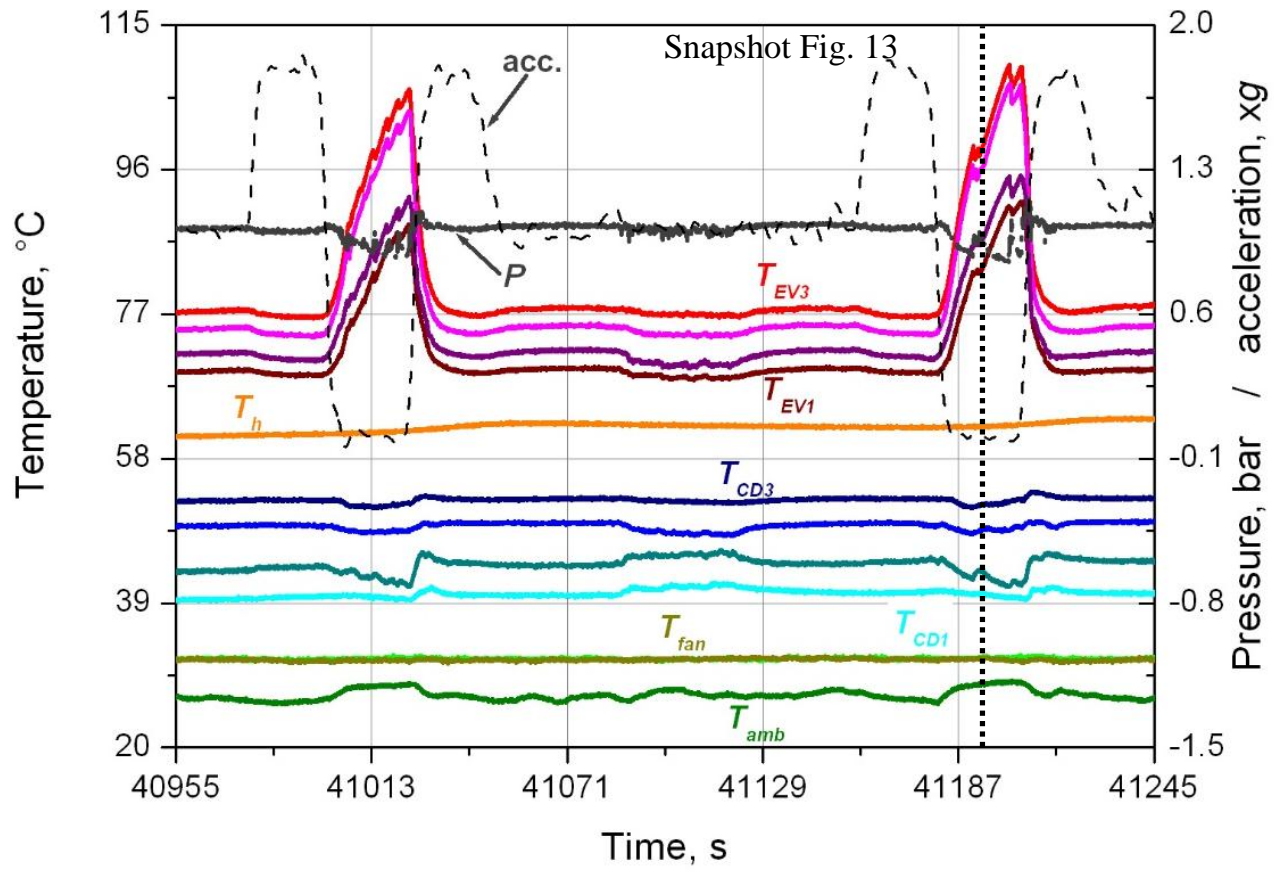

Fig. 12. Transient temperatures and pressure for two successive parabolas at $Q=150 \mathrm{~W}$ 


\section{ACCEPTED MANUSCRIPT}

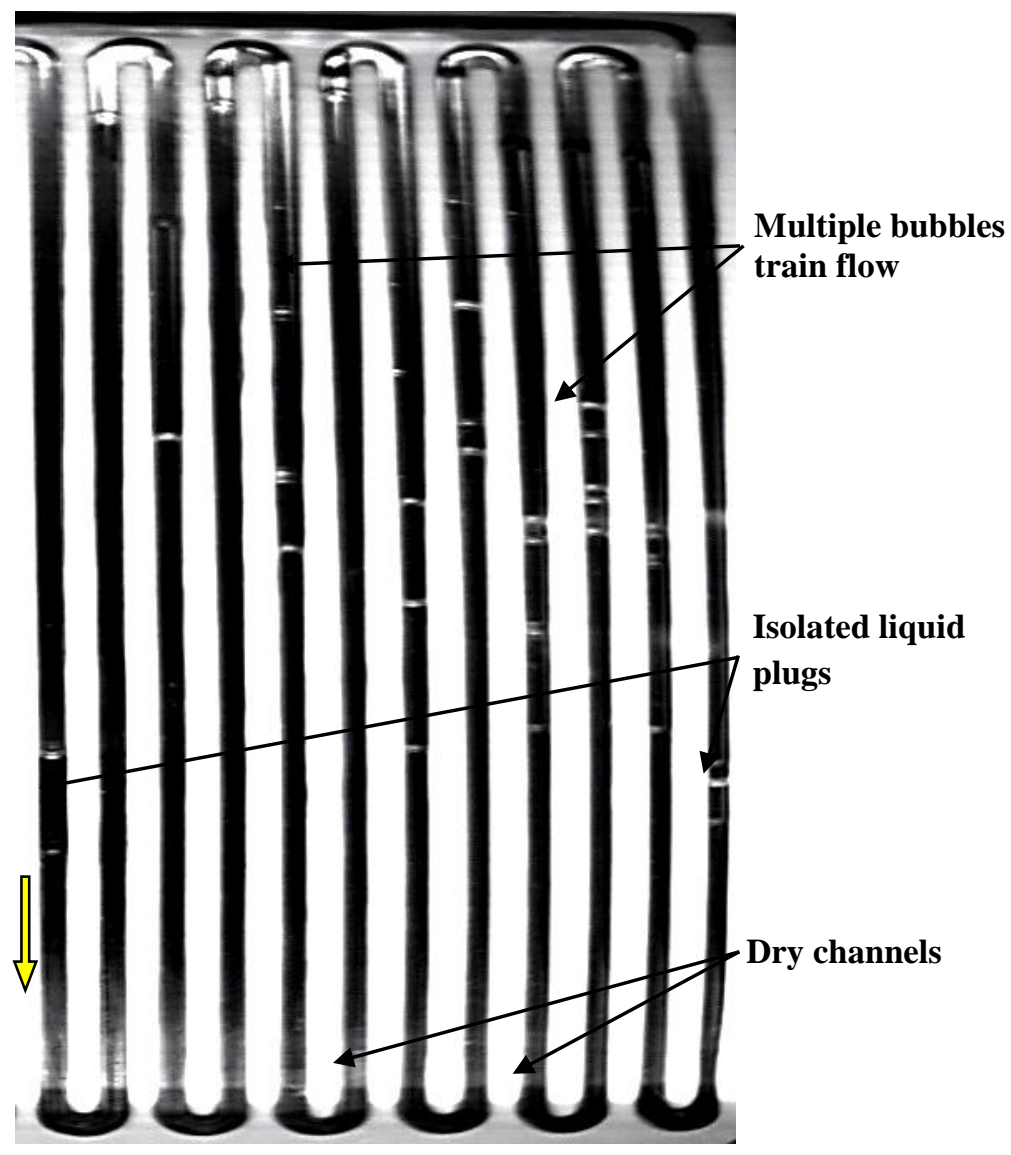

Fig. 13. Corresponding flow pattern in the right-half FPPHP during microgravity conditions at time indicated by dashed line of Fig. $12(Q=150 \mathrm{~W})$ 


\section{ACCEPTED MANUSCRIPT}
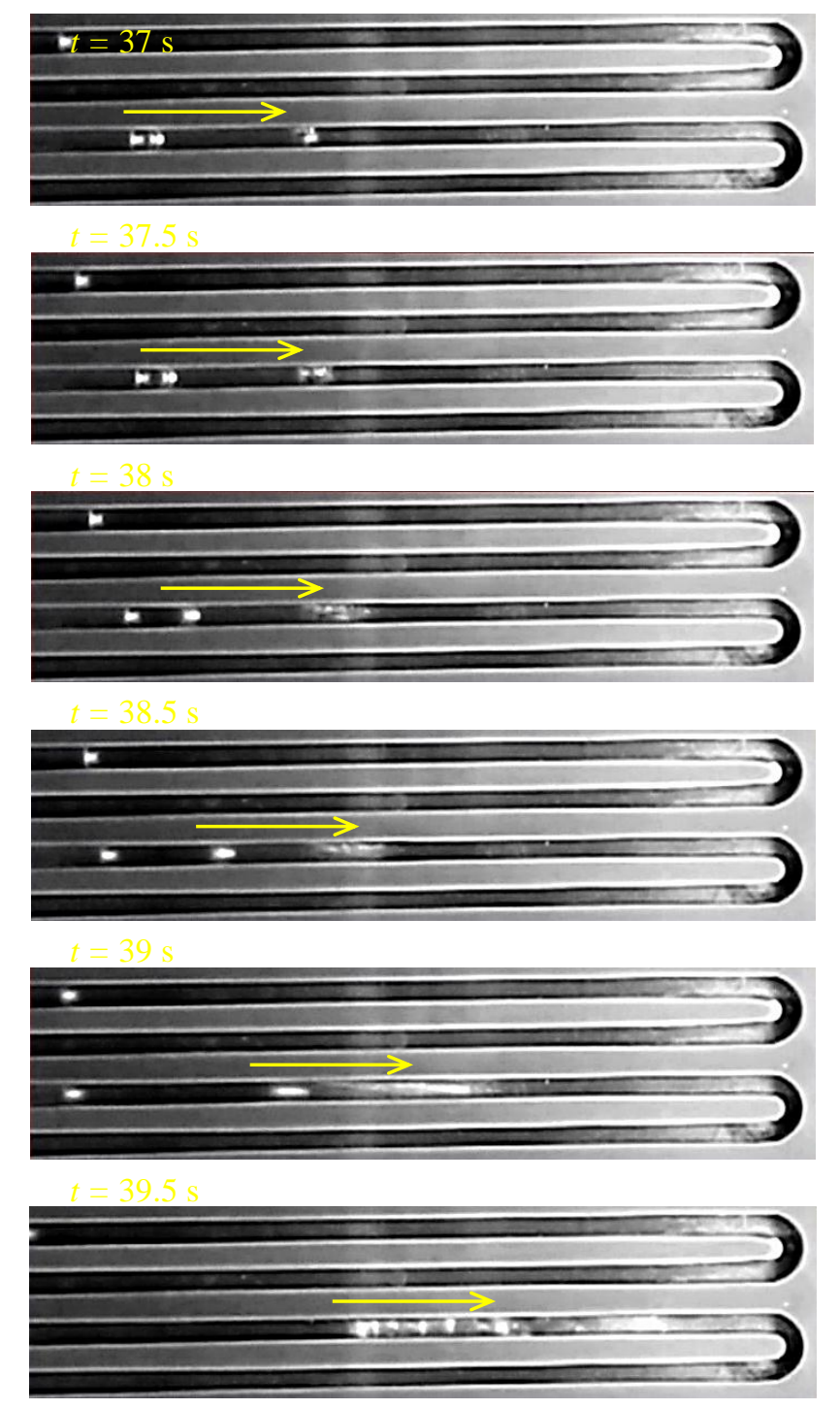

Fig. 14. Sequence of macro images of an isolated liquid plug during microgravity conditions

flowing towards the evaporator and subject to evaporation (parabolic flight, $Q=100 \mathrm{~W}$ ) 


\section{ACCEPTED MANUSCRIPT}

\section{Notes on the contributors}

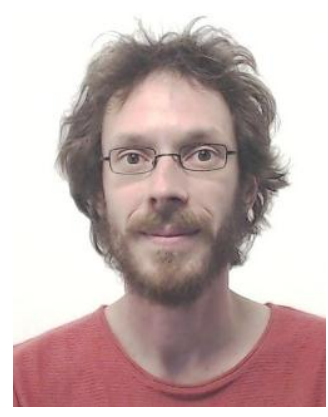

Vincent Ayel is an Assistant Professor of Thermal Sciences at ISAE-

ENSMA, Futuroscope-Chasseneuil, France. He received his Ph.D. in

Energetic and Thermal Sciences in 2003 from the University of Nantes,

France, relating to crystallization in the field of ice slurries. He carried out

research on PEM Fuel Cells as Post-doctoral at LEMTA, Nancy, France, in

2004, before working on liquid/vapor two-phase passive heat transfer devices such as heat pipes, pulsating heat pipes, and loop heat pipes at Pprime Institute, Poitiers, France. He is currently the head of the Thermal and Energy teaching Department of ENSMA since 2015. He is the coauthor of more than 45 scientific papers and 15 conference proceedings.

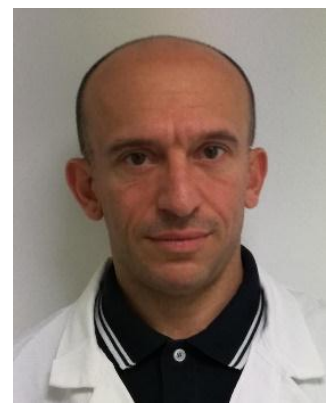

Lucio Araneo is an Assistant Professor at Politecnico di Milano, Italy.

He received his M.Sc. and Ph.D. degrees from Politecnico di Milano, and a M.Sc. from Ecole Nationale Supérieure du Pétrole et des Moteurs, France. He has been research fellow at the University of Darmstad, and visiting Professor at Politecnica de Valencia, Italy. He has been teaching Thermodynamics and Thermal Physics at Politecnico di Milano since 2002. His research activity is focused on the experimental study of two phase flows, particularly for sprays and for heat transfer phenomena. He participated in 12 ESA Parabolic Flight Campaigns on board of the ZERO-G aircraft with different experiments on liquid interphase behavior and on boiling and condensation. 


\section{ACCEPTED MANUSCRIPT}

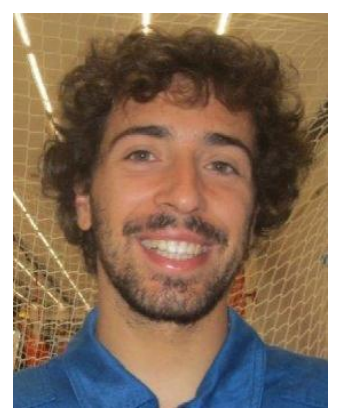

Pietro Marzorati is a mechanical plant designer at ADF Sistemi, Como, Italy since 2016. He received his Master's degree in 2015 in Energy and Heat Transfers Engineering at Polytecnico di Milano, Italy. He has also designed, constructed and tested next generation snowboards at Comera

Snowboards, Lecco, Italy.

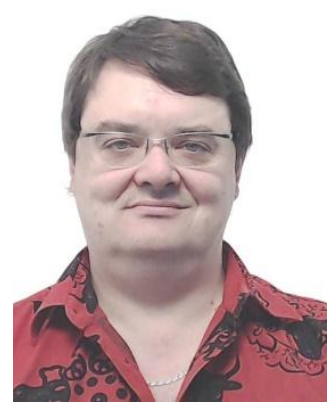

Cyril Romestant is a Research Engineer at Pprime Institute, based at ENSMA, Futuroscope-Chasseneuil, France. He received his Ph.D. in Energetic, Thermal Sciences and Combustion in 2000 from the University of Poitiers, France. His research contributions were particularly in the field of liquid/vapor two-phase passive heat transfer devices (heat pipes, loop heat pipes and rotating heat pipes). He is currently in charge of the experimental sector of the Laboratory of Thermal Sciences (axe COST) of Pprime Institute, and is working on two-phase devices for high dissipative cooling applications. He is the coauthor of more than 40 scientific papers. 


\section{ACCEPTED MANUSCRIPT}

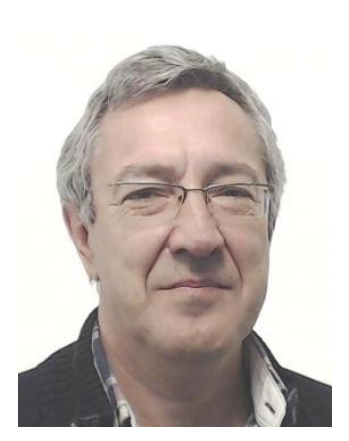

Yves Bertin is a Professor of Thermal Sciences at ISAE-ENSMA, Futuroscope-Chasseneuil, France. He received his Ph.D. degree in 1987 from the University of Poitiers. He has been Assistant Professor at ENSMA since 1988 and Professor since 2010. He has been teaching thermal sciences and thermal modeling, and has been the head of the Thermal and Energy teaching Department of ENSMA for 8 years. His research contributions were in the field of convective heat transfers in rotating engines, heat transfers in electrical motors, thermal systems modeling and, finally, two-phase liquid-vapor heat transfer passive devices (heat pipes, capillary pumped loops, and pulsating heat pipes). He has also been coordinator of various European (CleanSky) and national projects. He is the co-author of more than hundred of scientific papers and conference proceedings.

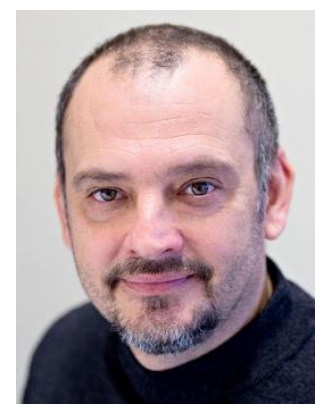

Marco Marengo is Professor of Thermal Engineering at the University of Brighton since 2014. He received his Ph.D. degree in 1996 from Politecnico di Milano, Italy. He has been Assistant Professor and Professor at University of Bergamo, Italy, from 1998 to 2016 . He is involved in different multidisciplinary research activities spanning from thermal management for space and ground applications to numerical simulations of interface dynamics. He is Editor of Atomization \& Sprays Journal. He has given more than 30 invited lectures in Universities, Conferences and Research Institutes. He has published 260 papers, among them about 60 in scientific journals. 